\title{
Pflege zwischen Kennzahlen und Qualität
}

\author{
Ingrid Smerdka-Arhelger
}

Online publiziert: 24. Oktober 2012

(C) Springer-Verlag Wien 2012

Spätestens seit der Veröffentlichung des Pflegethermometers durch das DIP (Deutsches Institut für angewandte Pflegeforschung e. V.) im Jahr 2009 ist belegt, in welchem Umfang Pflegekräfte in den letzten 10 Jahren in Krankenhäusern abgebaut worden sind - bei gleichzeitigem Anstieg der Fallzahlen der Patienten, höherer Multimorbidität und kürzerer Verweildauer. Auch die demografische Falle ist bekannt.

Parallel zu dieser Entwicklung gelingt es der Berufsgruppe der Ärzte, die Beschäftigungszahlen in den Kran- kenhäusern und ihre Gehälter in erheblichem Umfang zu erhöhen. Die Krankenkassen stellen bundesweit fest, dass reichlich Geld in ihren Kassen vorhanden ist.

Geld ist im System, aber es kommt nicht von selbst in den Pflegebereich. Was hindert die Pflegenden daran, sich für die pflegerisch adäquate Versorgung der Patienten und für die ausreichende Bezahlung ihrer pflegerischen Arbeit gesellschaftspolitisch zu engagieren? 